\title{
Advantages of Dose-Dense Methotrexate Protocol for Primary Central Nervous System Lymphoma: Comparison of Two Different Protocols at a Single Institution
}

\author{
Hiroshi AOKI, ${ }^{1}$ Ryosuke OGURA, ${ }^{1}$ Yoshihiro TsuKamoto, ${ }^{1}$ Masayasu OKADA, ${ }^{1}$ \\ Manabu NATSUMEDA, ${ }^{1}$ Mizuho ISOGAWA, ${ }^{1}$ Seiichi YosHIDA, ${ }^{1}$ and Yukihiko FujII ${ }^{1}$ \\ ${ }^{1}$ Department of Neurosurgery, Brain Research Institute, Niigata University, Niigata, Niigata
}

\begin{abstract}
The efficacy and toxicity of high-dose methotrexate (HD-MTX)-based chemotherapy were retrospectively reviewed in patients with primary central nervous system lymphoma (PCNSL). All immunocompetent patients with histologically or radiographically diagnosed PCNSL treated between 2006 and 2012 at Niigata University Hospital were enrolled. Thirty-eight patients with a diagnosis of PCNSL were treated with one of two regimens during different time periods. During the first period, from 2006 to 2009, three 3-week cycles of MPV (MTX + procarbazine + vincristine) were administered (MPV3 group). In the second period, from 2010 to 2012, five 2-week cycles of MTX were administered (MTX5 group). High-dose cytarabine was used in both groups following HD-MTX-based chemotherapy. Whole-brain radiotherapy was used for patients who did not attain a complete response (CR) based on magnetic resonance images. In the MPV3 group, 20 out of 23 patients (87\%) completed the planned treatment. The CR rate after chemotherapy was $30 \%$, and $57 \%$ after radiation therapy. Thirteen out of 15 patients $(87 \%)$ in the MTX5 group completed the planned treatment. The CR rates after chemotherapy and radiation therapy were $53 \%$ and $93 \%$, respectively. Renal dysfunction was assessed by measuring creatinine clearance rates, which were very similar in both groups. In terms of hematologic toxicity and other adverse reactions, there was no significant difference between the two groups. In conclusion, dose-dense MTX chemotherapy improved outcome with acceptable toxicity compared with the treatment schedule for three cycles of MPV treatment.
\end{abstract}

Key words: primary central nervous system lymphoma, high-dose methotrexate, complete response rate, toxicity

\section{Introduction}

Primary central nervous system lymphoma (PCNSL) is a rare brain tumor, but its incidence is rising among immunocompetent patients. ${ }^{5)}$ More than $60 \%$ of all cases of PCNSL occur among patients older than 60 years in Japan. ${ }^{5)}$ High-dose methotrexate (HD-MTX)based chemotherapy with or without radiotherapy is the standard treatment for PCNSL. However, the most effective parameters for MTX usage are unclear. The following five factors need to be considered: (1) dosage, (2) infusion speed, (3) number of cycles,

Received May 31, 2013; Accepted August 14, 2013
(4) length of interval, and (5) monotherapy or combination therapy. In terms of dosage, $1-8 \mathrm{~g} / \mathrm{m}^{2}$ of MTX has been adopted in various clinical trials, and $3.0 \mathrm{~g} / \mathrm{m}^{2}$ or more of MTX is widely acce pted..$^{2-4,6-9,11,12,14,19,21-30,32)}$ MTX appears to be readily distributed into the cerebrospinal fluid when $3.0 \mathrm{~g} / \mathrm{m}^{2}$ or more of MTX is administered. ${ }^{17)}$ Furthermore, a recent trial has investigated changing subsequent doses of MTX based on the plasma concentration of MTX. ${ }^{13)}$ For $100 \mathrm{mg} / \mathrm{kg}$ of MTX, a 3-hour infusion has been recommended because of optimal central nervous system (CNS) penetration. ${ }^{10)}$ For $8 \mathrm{~g} / \mathrm{m}^{2}$, a 4 to 6-hour infusion is commonly used. ${ }^{3,8,9,29)}$ Currently, some reports have indicated improved treatment results with an increased number of cycles of MTX.4,8,12,26,32) 
One of the essential roles of dose-intensity MTX treatment is to defer whole-brain radiation therapy (WBRT) during first-line treatment and thus decrease the risk for leukoencephalopathy, especially for elderly patients, and retain the option of re-treating with MTX at relapse. When MTX is administered, a 2-week interval would hypothetically be better than a 3-week interval between cycles. However, there are no reports to confirm this point.

Renal toxicity and myelosuppression are among the major side effects of MTX. However, when monitored closely, MTX can be administered with minimal side effects to patients, including the elderly. ${ }^{21,32)}$ It is extremely important to assess the optimal MTX treatment method, and these data will be critical when exploring new treatment options for PCNSL.

At Niigata University Hospital Department of Neurosurgery, we have used two different HD-MTXbased chemotherapy protocols consecutively. In this study, CR rates after completion of chemotherapy and radiation therapy, progression-free survival (PFS), and overall survival (OS) were assessed to determine the effectiveness of these two protocols. Furthermore, renal dysfunction, hematologic toxicity, and other adverse reactions of the two treatments were compared.

\section{Patients and Methods}

This study included 38 patients with PCNSL, who were newly diagnosed from January 2006 to December 2012 at Niigata University Hospital. Major inclusion criteria of this study were: immunocompetent PCNSL; less than 80 years; creatinine clearance of more than $0.5 \mathrm{ml} / \mathrm{min}$; and no apparent dissemination radiographically nor cytologically. Consecutive patients treated with chemotherapy were enrolled. The treatment group from the first period, from January 2006 to December 2009, was designated as the MPV3 group, and the latter group, receiving treatment from January 2010 to December 2012, was allotted to the MTX5 group.

\section{Treatment protocol}

Treatment protocols for both groups are indicated in Fig. 1. MPV3 patients were treated with three cycles of MPV treatment: $1.4 \mathrm{mg} / \mathrm{m}^{2}$ of vincristine (day 1), $100 \mathrm{mg} / \mathrm{m}^{2}$ of procarbazine (days 2-8), and $3.5 \mathrm{~g} / \mathrm{m}^{2}$ of MTX (day 10) in 3-week cycles. Next, leucovorin rescue was used as indicated below. After three cycles of chemotherapy, 1.5 or $2.0 \mathrm{~g} / \mathrm{m}^{2}$ of cytarabine (Ara-C, days 1,2) was intravenously administered; $2.0 \mathrm{~g} / \mathrm{m}^{2}$ of Ara-C was administered to patients 60 years old or younger, and $1.5 \mathrm{~g} / \mathrm{m}^{2}$
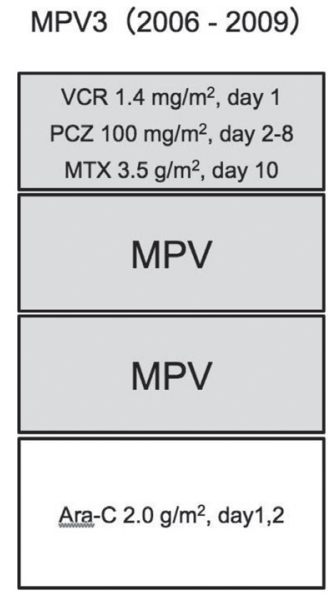

\pm WBRT 30Gy + 10 20Gy boost
MTX5 (2010 - 2012)

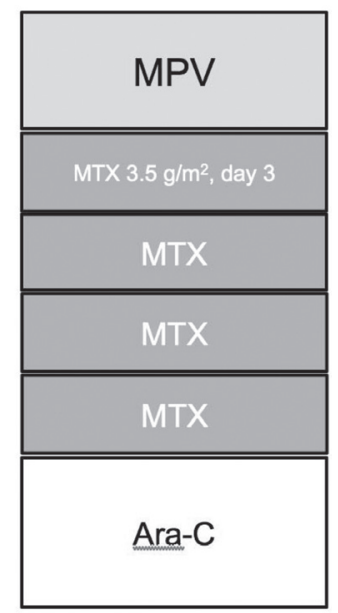

Fig. 1 Scheme of two treatment protocols. MPV3 contains three cycles of MPV treatment in 9 weeks, and MTX5 contains five cycles of MTX treatment in 10 weeks. Ara-C: cytarabine, MPV: methotrexate + procarbazine + vincristine, MTX: methotrexate, PCZ: procarbazine, VCR: Vincristine, WBRT: whole-brain radiotherapy.

for patients over 60 years old. For patients who did not attain CR based on evaluation by post-contrast magnetic resonance (MR) images, a total dose of 30 Gy of WBRT using conventional fractionation with or without 10-20 Gy of focal boosts was added. MTX5 patients were treated with a cycle of MPV followed by four cycles of the same MTX dose alone (day 3) in 2-week cycles. In brief, MTX was administered five times during 10 weeks in the MTX5 group. Ara-C and WBRT were administered using the same criteria as for the MPV3 group. In addition, for patients who attained CR after chemotherapy and had not received WBRT, a cycle of MPV chemotherapy was repeated every 4 months for 2 years. In both protocols, a creatinine clearance rate (Ccr) of more than $50 \mathrm{ml} / \mathrm{min}$ was confirmed before each cycle. Each $3.5 \mathrm{~g} / \mathrm{m}^{2}$ dose of MTX was administered over 3 hours. Leucovorin rescue was used from 24 hours after administration of MTX for 5 days. Before and after administration of MTX, hydration and urine alkalization were continued to maintain a urine output of more than $100 \mathrm{ml} / \mathrm{hr}$ and a urine $\mathrm{pH}$ of more than 7 .

Patients who had progressive disease or grade IV hematologic toxicity during chemotherapy also received WBRT or focal boosts to areas of persistent tumor after discontinuing chemotherapy. Steroid therapy was administered to all MPV3 patients as 10-30 mg of oral prednisolone. In contrast, MTX5 
patients received minimal doses of oral prednisolone for improving their symptoms in order to correctly determine the treatment efficacy on MR images.

\section{Patient characteristics}

Twenty-three and 15 patients were enrolled in the MPV3 and MTX5 groups, respectively. The main clinical features during diagnosis are shown in Table 1 . The median age at the time of diagnosis was 61 years (range: 17-75 years) and 63 years (range: 43-71 years), respectively. Seventeen patients $(74 \%)$ were men and $6(26 \%)$ were women in the MPV3 group, and 11 patients (73\%) were men and $4(27 \%)$ were women in the MTX5 group. The median Karnofsky performance status (KPS) was 60 in both groups. In the MPV3 group, PCNSL was diagnosed histologically by biopsy in 21 patients (91\%) and clinically without surgical procedures in 2 patients (9\%). In the MTX5 group, PCNSL diagnosis was made histologically by surgery, including one total removal, in 10 patients $(67 \%)$; by cerebrospinal fluid (CSF) cytology in 3 patients $(20 \%)$; and clinically in 2 patients $(13 \%)$. B-cell lymphoma was diagnosed in 19 patients (83\%) of the MPV3 group and 13 patients $(87 \%)$ of the MTX5 group.

\section{Response and toxicity criteria}

MR scans of the brain were repeated after surgery, chemotherapy, and radiotherapy. Further scans were performed every 2 months during follow-up evaluations for the first 2 years and every 3 months thereafter. Neuroradiographic response criteria as defined by Macdonald et al. were used. ${ }^{18)}$ Toxicity was graded using the National Cancer Institute Common Toxicity Criteria.

\section{Statistical methods}

The CR rates after chemotherapy and radiotherapy were assessed. Median PFS and median OS were estimated. Adverse effects including renal dysfunction and hematologic toxicity were also investigated. Categorical data were compared using Fisher's exact test, two-tailed p value. The survival curves were estimated according to the method of Kaplan and Meier and compared using the log rank test. PFS and OS were determined from the date of diagnosis to relapse and death or last visit.

\section{Results}

\section{Treatment completion}

Patients' treatment profiles are shown in Table 2. Twenty out of $23(87 \%)$ patients in the MPV3 group and 13 out of 15 (87\%) patients in the MTX5 group
Table 1 Lymphoma patient characteristics in two groups

\begin{tabular}{lcc}
\hline & MPV3 $(\mathrm{n}=23)$ & MTX5 (n = 15) \\
\hline $\begin{array}{l}\text { Age, years } \\
\text { (median) }\end{array}$ & $17-75(61)$ & $43-71(63)$ \\
Sex & & \\
$\quad$ Male & $17(74 \%)$ & $11(73 \%)$ \\
$\quad$ Female & $6(26 \%)$ & $4(27 \%)$ \\
KPS on admission & $40-90(60)$ & $30-90(60)$ \\
(median) & & \\
Diagnosis & & \\
$\quad$ Surgery & $0(0 \%)$ & $9(60 \%)$ \\
$\quad$ Removal & $21(91 \%)$ & $3(20 \%)$ \\
$\quad$ Biopsy & $0(0 \%)$ & $2(13 \%)$ \\
Cytology & $2(9 \%)$ & $13(87 \%)$ \\
Others & & $10(67 \%)$ \\
Pathology & $19(83 \%)$ & $2(13 \%)$ \\
B-cell lymphoma & $19(83 \%)$ & \\
DLBCL & $4(17 \%)$ & \\
Others & &
\end{tabular}

DLBCL: diffuse large B-cell lymphoma, KPS: Karnofsky performance status, MPV: methotrexate + procarbazine + vincristine, MTX: methotrexate, $\mathrm{N}$ : number.

Table 2 Treatment completion and complete response rate

\begin{tabular}{lccc}
\hline & $\begin{array}{c}\text { MPV3 } \\
(\mathrm{n}=23)\end{array}$ & $\begin{array}{c}\text { MTX5 } \\
(\mathrm{n}=15)\end{array}$ & $\begin{array}{c}\text { Fisher's test } \\
\text { results }\end{array}$ \\
\hline $\begin{array}{l}\text { MPV / MTX } \\
\text { complete }\end{array}$ & $20(87 \%)$ & $13(87 \%)$ & \\
$\begin{array}{l}\text { Ara-C complete } \\
\text { CR / PR / SD / PD }\end{array}$ & $78(78 \%)$ & $13(87 \%)$ & \\
$\begin{array}{l}\text { CR rate after } \\
\text { chemotherapy }\end{array}$ & $30 \%$ & $53 \%$ & 0.2 \\
$\begin{array}{l}\text { Response rate } \\
\text { Whole brain }\end{array}$ & $87 \%$ & $93 \%$ & \\
$\begin{array}{l}\text { Wadiotherapy } \\
\text { rad }\end{array}$ & $18(78 \%)$ & $7(47 \%)$ & 0.2 \\
$\begin{array}{l}\text { CR / PR / SD / PD } \\
\text { CR rate after } \\
\text { radiotherapy }\end{array}$ & $13 / 10 / 0 / 0$ & $14 / 1 / 0 / 0$ & \\
Response rate & $57 \%$ & $(93 \%)$ & 0.03 \\
\hline
\end{tabular}

CR: complete response, MPV: methotrexate + procarbazine + vincristine, MTX: methotrexate, PD: progressive disease, PR: partial response, SD: stable disease.

completed MTX treatment. Eighteen out of 23 (78\%) patients in the MPV3 group and 13 out of $15(87 \%)$ patients in the MTX5 group completed Ara-C treatment. Eighteen out of $23(78 \%)$ patients in the MPV3 group and 7 out of $15(47 \%)$ patients in the MTX5 group received WBRT following chemotherapy. In 
both groups, all patients completed the planned radiotherapy. Patients who did not attain CR received WBRT in both groups.

\section{Response of therapy}

Seven out of $23(30 \%)$ patients in the MPV3 group and 8 out of $15(53 \%)$ patients in the MTX5 group reached CR after chemotherapy. There was no significant difference between these two groups ( $p=$ $0.2)$. Thirteen out of $23(57 \%)$ patients in the MPV3 group and 14 out of 15 (93\%) patients in the MTX5 group attained CR after radiotherapy. The CR rate was significantly higher in the MTX5 group ( $p=0.03)$. $\mathrm{PR}, \mathrm{SD}, \mathrm{PD}$, and response rate are shown in Table 2.

\section{Progression-free survival and overall survival}

Kaplan-Meier curves of PFS and OS are shown in Fig. 2. Median follow-up periods were 39 (range: 7-72) months for the MPV3 group and 23 (range: 6-37) months for the MTX5 group (Table 3). Sixteen out of $23(70 \%)$ patients in the MPV3 group and 2 out of $15(13 \%)$ patients in the MTX5 group have so far suffered a relapse. Patients who had not received WBRT at relapse, additional MTX/MPV treatment and/ or WBRT were prioritized. Patients who had already received WBRT at relapse, a carboplatin + etoposide regimen, additional WBRT, stereotactic radiotherapy, or rituximab administration were considered as single therapies or in combination; best supportive care was selected for advanced disease. Estimated median PFS was 12 months in the MPV3 group and was not reached in the MTX5 group, which had significantly prolonged PFS ( $p=0.01)$. Fourteen out of $23(61 \%)$ patients in the MPV3 group have died so far, and no patients have died in the MTX5 group. Estimated median OS was 39 months in the MPV3 group and was not reached in MTX5 group, which also had significantly prolonged OS $(\mathrm{p}=0.01)$. Recurrences were confirmed in all deceased patients, including one who developed esophageal cancer.

\section{Treatment toxicity}

A total of 64 cycles of MTX were administered to 23 patients in the MPV3 group. In 3 patients, MTX was interrupted because of arrhythmia, esophageal cancer, or patient request. A total of 72 cycles of MTX were administered to 15 patients in the MTX5 group. In 2 patients, MTX was discontinued because of renal dysfunction or tumor progression. The most significant acute toxicity of MTX was renal dysfunction. Ccr before and after MTX treatment is indicated in Fig. 3. Mean Ccr before and after MTX treatment in the MPV3 group was $98 \mathrm{ml} / \mathrm{min}$ and $80 \mathrm{ml} / \mathrm{min}$, and $104 \mathrm{ml} / \mathrm{min}$ and $82 \mathrm{ml} / \mathrm{min}$ in the MTX5 group, respectively. There was no significant difference between these two groups.

Another major acute toxicity for chemotherapy involved hematologic indicators. Grade 4 toxicity in the form of neutropenia was observed in only one patient in the MPV3 group, and Ara-C was omitted for this patient. Grade 3 anemia was observed in only one patient in the MPV3 group. As already mentioned, 18 out of $23(78 \%)$ patients in the MPV3 group and 13 out of $15(87 \%)$ patients in the MTX5 group completed Ara-C treatment. Grade 4 neutropenia was observed in $16(89 \%)$ and in $12(92 \%)$ patients; grade 4 thrombocytopenia was observed in $5(28 \%)$ and in $2(15 \%)$ patients of the respective groups (Table 4). Grade 4 anemia was not observed in either group. There was no significant difference in incidence of any hematological adverse events between these two groups.

With regard to other adverse events, nausea (grade
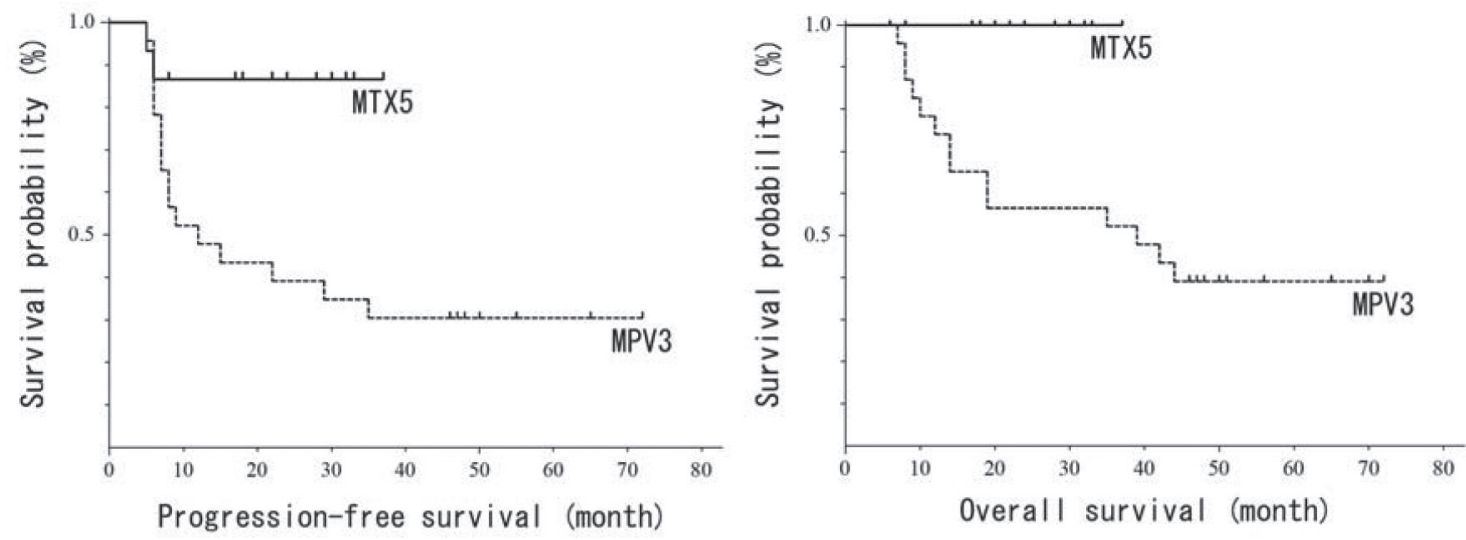

Fig. 2 Kaplan-Meier curves of progression-free and overall survival. MPV: methotrexate + procarbazine + vincristine, MTX: methotrexate. 
Table 3 Follow-up period and median progression-free and overall survival

\begin{tabular}{lccc}
\hline & $\begin{array}{c}\text { MPV3 } \\
(\mathrm{n}=23)\end{array}$ & $\begin{array}{c}\text { MTX5 } \\
(\mathrm{n}=15)\end{array}$ & $\begin{array}{c}\text { Log-rank test } \\
\text { results }\end{array}$ \\
\hline $\begin{array}{l}\text { Follow-up } \\
\text { period (m) }\end{array}$ & $39(7-72)$ & $23(6-37)$ & \\
Median PFS (m) & 12 & N.R. & 0.01 \\
Median OS (m) & 39 & N.R. & 0.01 \\
\hline
\end{tabular}

M: month, MPV: methotrexate + procarbazine + vincristine, MTX: methotrexate, N.R.: not reached, OS: overall survival, PFS: progression-free survival.
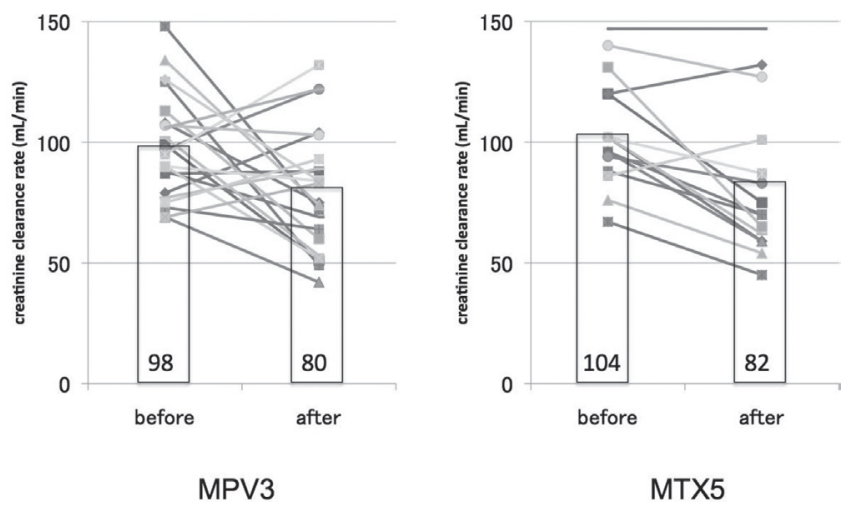

Fig. 3 Comparison of creatinine clearance rate at before and after methotrexate treatment. Bar graph shows average of creatinine clearance rate (Ccr) in each group. Line graph shows the Ccr of each patient. MPV: methotrexate + procarbazine + vincristine, MTX: methotrexate.

3) was observed in four patients in the MPV3 group and two patients in the MTX5 group. Liver dysfunction (grade 3) was observed in three patients in the MPV3 group. One patient in the MPV3 group developed deep venous thrombosis. In the MTX5 group, one patient developed photodermatosis, one had numbness of the upper limbs, and two with drugassociated skin eruption were observed. High fever (grade 3 or more) was not observed in either group.

\section{Discussion}

The present study reports the results of 38 patients treated with two different HD-MTX-based chemotherapy protocols during different periods of time. Dose-dense MTX chemotherapy, which means five 2-week cycles of MTX contrasted with three 3-week cycles of MPV, showed a treatment benefit in terms of the CR rate after chemotherapy and radiotherapy without additional toxicity.

Table 5 shows recent representative clinical trials
Table 4 Hematologic toxicities after chemotherapy

\begin{tabular}{|c|c|c|c|}
\hline & $\begin{array}{l}\text { MPV3 } \\
(\mathrm{n}=23)\end{array}$ & $\begin{array}{c}\text { MTX5 } \\
(\mathrm{n}=15)\end{array}$ & $\begin{array}{c}\text { Fisher's } \\
\text { test results }\end{array}$ \\
\hline \multicolumn{4}{|l|}{ After MPV / MTX } \\
\hline Neutropenia G3 & $3(13 \%)$ & $3(20 \%)$ & n.s. \\
\hline G4 & $1(4 \%)$ & $0(0 \%)$ & n.s. \\
\hline Thrombocytopenia G3 & $1(4 \%)$ & $0(0 \%)$ & n.s. \\
\hline G4 & $0(0 \%)$ & $0(0 \%)$ & n.s. \\
\hline Anemia G3 & $1(4 \%)$ & $0(0 \%)$ & n.s. \\
\hline G4 & $0(0 \%)$ & $0(0 \%)$ & n.s. \\
\hline \multicolumn{4}{|l|}{ After Ara-C } \\
\hline Neutropenia G4 & $\begin{array}{l}16 / 18 \\
(89 \%)\end{array}$ & $\begin{array}{l}12 / 13 \\
(92 \%)\end{array}$ & n.s. \\
\hline Thrombocytopenia G4 & $\begin{array}{c}5 / 18 \\
(28 \%)\end{array}$ & $\begin{array}{c}2 / 13 \\
(15 \%)\end{array}$ & n.s. \\
\hline Anemia G4 & $0 / 18(0 \%)$ & $0 / 13(0 \%)$ & n.s. \\
\hline \multicolumn{4}{|l|}{ Non-hematologic toxicity } \\
\hline Nausea G3 & $4(17 \%)$ & $2(15 \%)$ & n.s. \\
\hline Liver dysfunction G3 & $3(13 \%)$ & $0(0 \%)$ & n.s. \\
\hline DVT G2 & $1(4 \%)$ & $0(0 \%)$ & n.s. \\
\hline Numbness G3 & $0(0 \%)$ & $1(7 \%)$ & n.s. \\
\hline Drug eruption G2 & $0(0 \%)$ & $2(13 \%)$ & n.s. \\
\hline Photodermatosis G2 & $0(0 \%)$ & $1(7 \%)$ & n.s. \\
\hline Fever & $0(0 \%)$ & $0(0 \%)$ & n.s. \\
\hline
\end{tabular}

DVT: deep venous thrombosis, G2: grade 2, G3: grade 3, G4: grade 4, MPV: methotrexate + procarbazine + vincristine, MTX: methotrexate, n.s.: not significant.

using HD-MTX and data from the present study. First, Abrey et al. reported excellent clinical results from an MPV protocol in 2000. ${ }^{2)}$ The CR rate after chemotherapy was $58 \%$, and the median OS was 60 months. The outcome of this clinical trial, which included elderly patients, has served as the benchmark for subsequent trials. Shah et al., also at the Memorial Sloan-Kettering Cancer Center, reported that the CR rate was elevated to $78 \%$ by increasing the number of MTX cycles to seven and adding rituximab. ${ }^{26)}$ However, it should be noted that the incidence of neutropenia was significantly increased with the addition of rituximab. They speculated that increasing the number of cycles of MTX contributed to a better outcome. In a randomized phase 2 trial by the Eastern Cooperative Oncology Group, Ferreri et al. reported the treatment results of MTX monotherapy as part of the study. ${ }^{6}{ }^{6}$ The CR rate after chemotherapy was $18 \%$, and the median OS was 
Table 5 Published studies on PCNSL treated with the protocol containing HD-MTX and the present report

\begin{tabular}{|c|c|c|c|c|c|c|c|}
\hline & $\begin{array}{l}\text { Age, years } \\
\text { median }\end{array}$ & Treatment & $\begin{array}{c}\text { Dose } \\
\left(\mathrm{g} / \mathrm{m}^{2}\right)\end{array}$ & Interval & $\begin{array}{l}\text { Cycle of } \\
\text { treatment }\end{array}$ & $\begin{array}{c}\text { CR rate after } \\
\text { chemotherapy }\end{array}$ & $\begin{array}{l}\text { Median OS } \\
\text { (months) }\end{array}$ \\
\hline $\begin{array}{l}\text { Shah et al. } \\
(2007)^{26)}\end{array}$ & $\begin{array}{c}30-76 \\
57\end{array}$ & R-MPV & 3.5 & 2 weeks & $5-7$ & $78 \%$ & N.R. \\
\hline $\begin{array}{l}{ }^{*} \text { Ferreri et al. } \\
(2009)^{6)}\end{array}$ & $\begin{array}{c}27-72 \\
53\end{array}$ & MTX & 3.5 & 3 weeks & 4 & $18 \%$ & $<12$ \\
\hline $\begin{array}{l}\text { Thiel et al. } \\
(2010)^{28)}\end{array}$ & $\begin{array}{c}55-69 \\
63\end{array}$ & MTX & 4.0 & 2 weeks & 6 & $35 \%$ & 32.4 \\
\hline MPV3 & $\begin{array}{c}17-75 \\
61\end{array}$ & MPV & 3.5 & 3 weeks & 3 & $30 \%$ & 39 \\
\hline MTX5 & $\begin{array}{c}43-71 \\
63\end{array}$ & MPV/MTX & 3.5 & 2 weeks & 5 & $53 \%$ & N.R. \\
\hline
\end{tabular}

*MTX alone protocol out of two groups in the study. CR: complete response, HD: high-dose, MPV: methotrexate + procarbazine + vincristine, MTX: methotrexate, N.R.: not reached, OS: overal survival, R-MPV: rituximab + MPV.

less than 12 months. These results were inferior to previous reports, suggesting a disadvantage for a 3-week interval during MTX treatment. Based on these findings and results, dose-dense MTX chemotherapy, shortening intervals, and increasing the number of cycles can be expected to improve outcome.

The results reported by Thiel et al. were important as one of the few phase 3 trials for PCNSL. ${ }^{28)}$ Patients in this trial underwent six cycles of MTX treatment combined with ifosphamide with an interval of 2 weeks. The CR rate after chemotherapy was $35 \%$, and the median OS was $32-37$ months. It is interesting that no significant improvement in OS was noted by adding WBRT. Cobert et al. reported clinical results of patients, including the elderly, treated with an average of 11 cycles of $8 \mathrm{~g} / \mathrm{m}^{2} \mathrm{MTX}^{4)}$ The median OS was 7 years, with only a small percentage of patients experiencing severe toxicity. The disadvantage of this protocol is the long treatment period, which includes maintenance therapy every 3 months.

In the current study, the CR rate was assessed as the clinical outcome because of a short follow-up period. There are some reports that the CR rate is significantly associated with long-term $\mathrm{OS},{ }^{15,28)}$ so it may be a useful tool in the interest of time. However, caution should be observed in that the correlation between CR and OS may be altered by inclusion of steroids or radiotherapy. When the patients in this study were grouped according to the recursive positioning analysis (RPA) classification, ${ }^{1)}$ there were four class $1(<50$ years $)$ patients (two in the MPV3 group and two in the MTX5 group). All four patients attained CR after the initial treatment, and three out of four patients attained CR after chemotherapy without radiotherapy. So, younger patients could be considered to have good prognoses. Furthermore, there was no significant difference in prognoses between class 2 (age $\geq 50$; KPS $\geq 70$ ) and class 3 (age $\geq 50$; KPS $<70$ ) (data not shown). We need to evaluate the usefulness of $\mathrm{RPA}$ as a prognostic factor of OS after evaluating patients' data for longer follow-up periods.

Obscured by the question of how to use MTX effectively is the issue of how to defer WBRT from the initial therapy. According to the National Comprehensive Cancer Network, 'WBRT may increase toxicity, especially in patients over 60 years of age and may be withheld in the primary setting, ${ }^{20)}$ From data collected from the previous studies at Niigata University, a substantial number of elderly patients who maintain CR have progressive leukoencephalopathy, and 30 Gy or more WBRT has been considered to be the most influential cause. ${ }^{31)}$ Avoiding treatment-related leukoencephalopathy 
while maximally utilizing MTX is expected to improve the quality of life in patients with PCNSL. From that point of view, temozolomide, which has minimal adverse effects, is a promising drug, and a clinical trial using it has been reported..$^{16,19,22)}$ In contrast, use of high-dose chemotherapy followed by autologous stem-cell transplantation is difficult in elderly people and tends to be applied in younger patients. However, since young patients generally have better prognoses from the outset, the wisdom of applying high-risk treatment to such cases needs to be debated. In the next decade, it is expected that the treatment of PCNSL will be standardized by the results of clinical trials, and the era of MTX-based chemotherapy is likely to continue until more effective treatments are established.

In conclusion, five 2-week cycles of MTX chemotherapy improved the CR rate with acceptable toxicity compared to three 3-week cycles of MPV treatment. Furthermore, it is essential to observe prognosis and functional outcomes, including OS and late toxicity. As a cornerstone for future development, a treatment strategy that fully utilizes MTX is desired.

\section{Acknowledgments}

The authors would like to thank Dr. Hitoshi Takahashi and Dr. Akiyoshi Kakita for histological diagnosis, Dr. Hidefumi Aoyama for radiotherapy, Dr. Takeyoshi Eda for chemotherapy, and Emiko Aiba for assessment of cognitive function.

\section{Conflicts of Interest Disclosure}

The authors have no conflict of interest or any financial disclosures to report. All authors who are members of The Japan Neurosurgical Society (JNS) have registered Self-reported COI Disclosure Statement Forms online through the website for JNS members.

\section{References}

1) Abrey LE, Ben-Porat L, Panageas KS, Yahalom J, Berkey B, Curran W, Schultz C, Leibel S, Nelson D, Mehta M, DeAngelis LM: Primary central nervous system lymphoma: the Memorial Sloan-Kettering Cancer Center prognostic model. J Clin Oncol 24: 5711-5715, 2006

2) Abrey LE, Yahalom J, DeAngelis LM: Treatment for primary CNS lymphoma: the next step. J Clin Oncol 18: 3144-3150, 2000

3) Chamberlain MC, Johnston SK: High-dose methotrexate and rituximab with deferred radiotherapy for newly diagnosed primary B-cell CNS lymphoma. Neuro- oncology 12: 736-744, 2010

4) Cobert J, Hochberg E, Woldenberg N, Hochberg F: Monotherapy with methotrexate for primary central nervous lymphoma has single agent activity in the absence of radiotherapy: a single institution cohort. J Neurooncol 98: 385-393, 2010

5) Committee of Brain Tumor Registry of Japan: Report of brain tumor registry of Japan (1984-2000). Neurol Med Chir (Tokyo) 49: 1-101, 2009

6) Ferreri AJ, Reni M, Foppoli M, Martelli M, Pangalis GA, Frezzato M, Cabras MG, Fabbri A, Corazzelli G, Ilariucci F, Rossi G, Soffietti R, Stelitano C, Vallisa D, Zaja F, Zoppegno L, Aondio GM, Avvisati G, Balzarotti M, Brandes AA, Fajardo J, Gomez H, Guarini A, Pinotti G, Rigacci L, Uhlmann C, Picozzi P, Vezzulli P, Ponzoni M, Zucca E, Caligaris-Cappio F, Cavalli F; International Extranodal Lymphoma Study Group (IELSG): High-dose cytarabine plus high-dose methotrexate versus high-dose methotrexate alone in patients with primary CNS lymphoma: a randomised phase 2 trial. Lancet 374: 1512-1520, 2009

7) Gerard LM, Imrie KR, Mangel J, Buckstein R, Doherty M, Mackenzie R, Cheung MC: High-dose methotrexate based chemotherapy with deferred radiation for treatment of newly diagnosed primary central nervous system lymphoma. Leuk Lymphoma 52: 1882-1890, 2011

8) Green MR, Chamberlain MC: Renal dysfunction during and after high-dose methotrexate. Cancer Chemother Pharmacol 63: 599-604, 2009

9) Herrlinger U, Korfel A, Hebart H, Schlegel U, Plasswilm L, Illerhaus G, Finke J, Krüger W, Montemurro M, Wolf T, Thiel E, Bamberg M, Weller M, Kanz L; Centers for Neuro-Oncology and Lymphoma, University of Tubingen, Germany: Meeting report: primary central nervous system lymphoma: standards of care and future perspectives. Onkologie 28: 109-111, 2005

10) Hiraga S, Arita N, Ohnishi T, Kohmura E, Yamamoto K, Oku Y, Taki T, Sato M, Aozasa K, Yoshimine T: Rapid infusion of high-dose methotrexate resulting in enhanced penetration into cerebrospinal fluid and intensified tumor response in primary central nervous system lymphomas. J Neurosurg 91: 221-230, 1999

11) Hohaus S, Teofili L, Balducci M, Manfrida S, Pompucci A, D’Alo' F, Massini G, Larocca LM, Marra R, Storti S: Combined Modality Treatment Including Methotrexate-Based Chemotherapy For Primary CENTRAL Nervous System Lymphoma: A Single Institution Experience.Mediterr J Hematol Infect Dis 1: e2009020, 2009

12) Illerhaus G, Marks R, Müller F, Ihorst G, Feuerhake F, Deckert M, Ostertag C, Finke J: High-dose methotrexate combined with procarbazine and CCNU for primary CNS lymphoma in the elderly: results of a prospective pilot and phase II study. Ann Oncol 20: 319-325, 2009

13) Joerger M, Ferreri AJ, Krähenbühl S, Schellens JH, Cerny T, Zucca E, Huitema AD: Dosing algorithm to target a predefined AUC in patients with primary 
central nervous system lymphoma receiving high dose methotrexate. Br J Clin Pharmacol 73: 240-247, 2012

14) Joerger M, Huitema AD, Illerhaus G, Ferreri AJ: Highdose methotrexate in patients with primary central nervous system lymphoma: does drug exposure really matter? Leuk Lymphoma 52: 1825-1827, 2011

15) Korfel A, Martus P, Nowrousian MR, Hossfeld DK, Kirchen H, Brücher J, Stelljes M, Birkmann J, Peschel C, Pasold R, Fischer L, Jahnke K, Thiel E; German primary central nervous system lymphoma Study Group (G-PCNSL-SG): Response to chemotherapy and treating institution predict survival in primary central nervous system lymphoma. Br J Haematol 128: 177-183, 2005

16) Kurzwelly D, Glas M, Roth P, Weimann E, Lohner H, Waha A, Schabet M, Reifenberger G, Weller M, Herrlinger U: Primary CNS lymphoma in the elderly: temozolomide therapy and MGMT status. J Neurooncol 97: 389-392, 2010

17) Lippens RJ, Winograd B: Methotrexate concentration levels in the cerebrospinal fluid during high-dose methotrexate infusions: an unreliable prediction. Pediatr Hematol Oncol 5: 115-124, 1988

18) Macdonald DR, Cascino TL, Schold SC, Cairncross JG: Response criteria for phase II studies of supratentorial malignant glioma. J Clin Oncol 8: 1277-1280, 1990

19) Makino K, Nakamura H, Hide T, Kuratsu J: Salvage treatment with temozolomide in refractory or relapsed primary central nervous system lymphoma and assessment of the MGMT status. J Neurooncol 106: 155-160, 2012

20) National Comprehensive Cancer Network: NCCN Clinical Practice Guidelines in Oncology (NCCN Guidelines ${ }^{\circledR}$ ). Central Nervous System Cancers Version 2. 19-21, 2011

21) Ney DE, Reiner AS, Panageas KS, Brown HS, DeAngelis LM, Abrey LE: Characteristics and outcomes of elderly patients with primary central nervous system lymphoma: the Memorial SloanKettering Cancer Center experience. Cancer 116: 4605-4612, 2010

22) Omuro AM, Taillandier L, Chinot O, Carnin C, Barrie M, Hoang-Xuan K: Temozolomide and methotrexate for primary central nervous system lymphoma in the elderly. J Neurooncol 85: 207-211, 2007

23) Omuro A, Taillandier L, Chinot O, Sierra Del Rio M, Carnin C, Barrie M, Soussain C, Tanguy ML, Choquet S, Leblond V, Hoang-Xuan K; ANOCEF Group (French Neuro-Oncology Association): Primary CNS lymphoma in patients younger than 60: can whole-brain radiotherapy be deferred? J Neurooncol 104: 323-330, 2011

24) Plotkin SR, Betensky RA, Hochberg FH, Grossman SA, Lesser GJ, Nabors LB, Chon B, Batchelor TT: Treatment of relapsed central nervous system lymphoma with high-dose methotrexate. Clin Cancer Res 10: 5643-5646, 2004

25) Poortmans PM, Kluin-Nelemans HC, Haaxma-Reiche H, Van't Veer M, Hansen M, Soubeyran P, Taphoorn
M, Thomas J, Van den Bent M, Fickers M, Van Imhoff G, Rozewicz C, Teodorovic I, van Glabbeke M; European Organization for Research and Treatment of Cancer Lymphoma Group: High-dose methotrexate-based chemotherapy followed by consolidating radiotherapy in non-AIDS-related primary central nervous system lymphoma: European Organization for Research and Treatment of Cancer Lymphoma Group Phase II Trial 20962. J Clin Oncol 21: 4483-4488, 2003

26) Shah GD, Yahalom J, Correa DD, Lai RK, Raizer JJ, Schiff D, LaRocca R, Grant B, DeAngelis LM, Abrey LE: Combined immunochemotherapy with reduced whole-brain radiotherapy for newly diagnosed primary CNS lymphoma. J Clin Oncol 25: 4730-4735, 2007

27) Silvani A, Salmaggi A, Eoli M, Lamperti E, Broggi G, Marras CE, Fariselli L, Milanesi I, Fiumani A, Gaviani P, Erbetta A, Giovagnoli AR, Pollo B, Botturi A, Boiardi A: Methotrexate based chemotherapy and deferred radiotherapy for primary central nervous system lymphoma (PCNSL): single institution experience. J Neurooncol 82: 273-279, 2007

28) Thiel E, Korfel A, Martus P, Kanz L, Griesinger F, Rauch M, Röth A, Hertenstein B, von Toll T, Hundsberger T, Mergenthaler HG, Leithäuser M, Birnbaum T, Fischer L, Jahnke K, Herrlinger U, Plasswilm L, Nägele T, Pietsch T, Bamberg M, Weller M: Highdose methotrexate with or without whole brain radiotherapy for primary CNS lymphoma (G-PCNSLSG-1): a phase 3, randomised, non-inferiority trial. Lancet Oncol 11: 1036-1047, 2010

29) Watanabe T, Katayama Y, Yoshino A, Komine C, Yokoyama T, Fukushima T: Long-term remission of primary central nervous system lymphoma by intensified methotrexate chemotherapy. J Neurooncol 63: 87-95, 2003

30) Welch MR, Omuro A, DeAngelis LM: Outcomes of the oldest patients with primary CNS lymphoma treated at Memorial Sloan-Kettering Cancer Center. Neuro-oncology 14: 1304-1311, 2012

31) Yamanaka R, Morii K, Shinbo Y, Takeuchi S, Tamura T, Hondoh H, Takahashi H, Onda K, Takahashi H, Tanaka R: Modified ProMACE-MOPP hybrid regimen with moderate-dose methotrexate for patients with primary CNS lymphoma. Ann Hematol 84: 447-455, 2005

32) Zhu JJ, Gerstner ER, Engler DA, Mrugala MM, Nugent W, Nierenberg K, Hochberg FH, Betensky RA, Batchelor TT: High-dose methotrexate for elderly patients with primary CNS lymphoma. Neuro-oncology 11: 211-215, 2009

Address reprint requests to: Hiroshi Aoki, MD, Department of Neurosurgery, Brain Research Institute, Niigata University, 1-757 Asahimachi-dori, Niigata, Niigata 951-8585, Japan. e-mail: aoki1123@bri.niigata-u.ac.jp 